\title{
AMÉRICA LATINA Y EL NUEVO ORDEN INTERNACIONAL
}

\author{
Jorge Gilbert Ceballos ${ }^{1}$
}

Adiós muro de Berlín. Bienvenido nuevo shopping mall de Berlín.

\section{INTRODUCCIÓN}

Con la caída del muro de Berlín y el desmantelamiento de la ex-Unión Soviética y los "socialismos históricos", la última moda en el mundo económico y la academia es hablar del neoliberalismo y la economía de mercado libre. Contrario al entendimiento de este modelo cuando fue concebido en Europa durante el siglo diecinueve, el neoliberalismo actual y sus políticas librecambistas no buscan reproducir ese viejo sistema, sino que por el contrario, es algo que se engendra dentro de lo que se denomina el "nuevo orden internacional".

El capitalismo mundial, especialmente el de las sociedades ricas e industrializadas del Norte, están optimistas y hablan acerca de la democratización, transición y oportunidades de crecimiento, especialmente en regiones como Asia y América Latina. Países como Taiwán, Singapur, Costa Rica, Chile se presentan al resto del mundo como modelos que han logrado combinar exitosamente un liberalismo económico junto a una democracia política ${ }^{2}$. De esta manera, el Tercer Mundo es invitado a seguir dichos modelos para alcanzar una casi instantánea modernidad que les permita eliminar sus subdesarrollos crónicos.

Este optimismo, sin embargo, se contradice con la realidad del llamado Tercer Mundo, en donde la desnutrición y la mortalidad infantil, el hambre, la pobreza y la cesantía han aumentado dramáticamente durante las décadas finales del siglo veinte. Mucho se ha escrito acerca de las fallas de los "socialismos históricos", pero muy pocos se atreven a comentar hoy día acerca de las fallas del "capitalismo desarrollista" tal como se practica en las regiones del Sur. ${ }^{3}$

En el pasado, antes de la crisis final del socialismo histórico el modelo capitalista fue promovido como una forma de desarrollo en el Tercer Mundo, a través de la promoción de un Estado al servicio de toda la nación para eliminar la desigualdad y la pobreza de la población. A pesar que este capitalismo desarrollista nunca logró sus metas. sin embargo fue

\footnotetext{
' Director del Center for Latin American Studies en la ciudad de Olympia. Wishington y profesor de Estudios Latinoamericanos en el Evergreen State College.

${ }^{2}$ Ver Jonathan Kandell, "Prosperity Born of Pain. The New York Time Muga-ine. July 7, 1991, pp. 15-16. Citado por Jorge Neff en Democratic Transition and the Entrenchmen of Awhoritaran Capitalism in Chile. Paper presentado en The Rocky Mountain Conference of Latin American Studies. Vancouver. B.C. celebrada entre el 31 de Marzo y el 3 de abril de 1993.

${ }^{3}$ El término Sur se refiere geográficamente a todas las naciones de América Latina y el Caribe, Asia y Africa. Del mismo modo. el Norte comprende a los centros de poder que constiturdos por los países altamente industrializados y las clases políticas que los gobiernan tales como Estados Unidos, Europa y Japón.
} 
definido y organizado alrededor de dichos objetivos.

La percepción de la realidad del Tercer Mundo por parte de los países ricos e industrializados del Norte se basan en análisis simplistas los cuales la mayoría de las veces sólo intentan justificar el control y dominación de las economías del Sur de acuerdo a sus propios intereses. Así, estos análisis intentan explicar un conjunto de elementos objetivos diferentes e interconectados entre sí, como a la vez, prescribir como soluciones ciertos tipos de democracias "protegidas y restringidas", cuyas metas finales son: reducción de la tasa de endeudamiento externo, control de la inflación, disminución de los gastos públicos combinados con elecciones formales junto a la aplicación de políticas de privatización. Estas son en general, las fórmulas promovidas por el Fondo Monetario Internacional (FMI), el Banco Interamericano de Desarrollo (BID) y el Banco Mundial (BM) junto a otras agencias crediticias internacionales para alcanzar las ansiadas metas de la modernización y el desarrollo de América Latina y otras regiones del planeta. ${ }^{4}$

Estudios acerca de la modemización y de las denominadas "teorías desarrollistas" comenzaron a popularizarse a partir de la década de los sesenta, existiendo hoy día una abundante bibliografía al respecto. ${ }^{5}$ Los programas desarrollistas elaborados por la Comisión Económica Para América Latina (CEPAL) durante la administración del Presidente John Kennedy constituyen un buen reflejo de los intentos de transformación de América Latina.

Para el observador casual, a partir de la última década del siglo veinte varias regiones de Asia, Africa y América Latina pueden aparecer como sociedades modernas y democráticas, pero sobretodo, abiertas al comercio internacional. Sin embargo, esta ligera impresión requiere de un análisis más detallado para entender como el modelo neoliberal opera dentro en el nuevo orden internacional controlado por un grupo de corporaciones multinacionales. ¿Cómo es posible entender la economía de libre mercado y el neoliberalismo cuando las corporaciones transnacionales con su control centralizado del dinero, sus regulaciones de precios y ganancias, y sus sistemas centralizados de administración dominan la economía mundial? Antes de discutir estas y otras importantes cuestiones, observemos el contexto del nuevo orden internacional.

\section{EL NUEVO ORDEN MUNDIAL}

Durante los últimos años el mundo ha cambiado drásticamente. La gran confrontación entre capitalismo y socialismo, la cual empezó en 1917 con la Revolución Rusa, y continuó a través de la Guerra Fría después de la Segunda Guerra Mundial hasta la década de los ochenta, terminó en 1989 con la caída del muro de Berlín. El prolongado y profundo conflicto que dividió al mundo oriental y occidental, no existe más.

Dentro de este contexto, sin embargo, el mundo se aproxima al siglo veintiuno con una nueva crisis y confrontación; esta vez, entre el Norte y el Sur o entre las sociedades ricas e industrializadas del Norte en contra de las sociedades pobres y subdesarrolladas del Sur; o sea entre el Primero y el Tercer Mundo. Algunos ejemplos significativos de esta situación

\footnotetext{
+ Contradictoriamente, al final del siglo veinte, cuando el triunfo del capitalismo ha sido anunciado a través de todo el mundo. el Banco Mundial publicó su Infome sobre el desarollo mundial 1990 , en el cual enfatiza la potriza cono uno de los problemas más grande de la década. De acuerdo al Banco Mundial "mil millones de personas a trates del mundo viven con un ingreso anual equivalente a 370 dólares".

Algunos de estos estudios son: Osvaldo Sunkel, "National Development Policy and Extermal Dependence in Latin America". Joumal of Development Studies. (1969-1970); also "Transnational Capital and National desintegration in Latin America". Socid and Economic Studies, (marzo 1993); Aníbal Pinto, "Notas sobre desarollo, subdesarrolloy dependencia," El Trimestre Económico. Volumen 39 (2), \# 154 (abril-junio 1972): Raúl Prebish. "International Trade and Payments in an Era of Coexistence." Anerican Economic Review: (XLIX, 1959).
} 
son las invasiones de Granada y Panamá, los conflictos en Centro América durante los ochenta y parte de los noventa, la guerra en contra de Irak, el bloqueo a Cuba y Libia, las situaciones de Haití y Somalia, etc. En este contex to no estamos hablando más acerca del Tercer Mundo. sino que del último mundo, el mundo de los marginalizados y condenados de la tierra.

\section{Los nuevos polos: el norte y el sur}

A partir del término de los "socialismos históricos" se observa un mundo con una alta concentración de capitales en las manos de unas pocas naciones del Norte congregadas en el denominado Grupo de los Siete: Alemania, Canadá, Estados Unidos, Francia, Inglaterra, Italia y Japón. Estos siete países, con una población de 800 millones de habitantes, o sea el $20 \%$ de la población mundial, controlan al resto del mundo, es decir, 4.000 millones de habitantes o el $80 \%$ de las personas que habitan en Africa, Asia América Latina y El Caribe. Económicamente hablando, el Norte con $20 \%$ de la población mundial reciben $82,7 \%$ de la riqueza mundial mientras que el Sur tiene sólo acceso al $17.3 \%$ de las misma (Richard: 1993: 34). En 1960, el 20\% de la población mundial más pudiente tenían ingresos 30 veces más altos que el $20 \%$ más pobre; en 1990 estos niveles eran 60 veces más altos. En la naciones subdesarrolladas los sectores más ricos concentran entre el 10 y $15 \%$ de sus poblaciones los cuales controlan la casi totalidad de la economía y recursos naturales. En América LAtina, el 10\% de la población controla el 95\% de la tierra arable (Castro: 1993: 15).

El mismo $20 \%$ de los habitantes más pudientes del planeta que habitan en el Primer Mundo controlan $81.2 \%$ del comercio mundial, $80.6 \%$ de las inversiones internas, $94.6 \%$ de todos los préstamos y el $80.5 \%$ de las inversiones mundiales. Del mismo modo, el $25 \%$ de la población que habitan en los países ricos e industrializados consumen $70 \%$ de la energía mundial, $75 \%$ de los metales, $80 \%$ de las maderas y $60 \%$ de los alimentos del planeta (Ibíd.). De esta manera, el actual orden internacional no puede existir sin reproducir la desigualdad social. Si el resto de los habitantes del planeta consumieran con los mismos niveles en que lo hacen los países más poderosos y desarrollados del Norte, éste simplemente agotaría todos sus recursos y no podríamos existir. Así, para mantener la actual estructura mundial ha emergido una elite internacional que controla la economía y las finanzas a nivel mundial, el poder militar, la cultura y los medios de comunicaciones de masas. Este orden internacional es mantenido a un costo de U\$900 mil millones destinados a equipos militares por parte de las naciones ricas del planeta (Richard: 1993: 34).

Debido a que la "amenaza roja" del comunismo se la llevó el viento y para legitimizar a este nuevo orden internacional, se intenta ideologizar la nueva confrontación regional presentando al Sur como el nuevo enemigo del Norte. En esta visión, se utilizan elementos tales como la existencia de poderosos y peligrosos productores de drogas y narcotraficantes, inestabilidad política, terrorismo, crisis y conflictos regionales que producen una fuerte inmigración ilegal, junto a una alarmante destrucción ecológica, todos productos del Sur y los cuales ponen en serio peligro la existencia misma de los países del Norte. A pesar que esta es una antigua confrontación entre ambas regiones, actualmente ha alcanzado una nueval etapa presentando caracteres cualitativos muy diferentes a los del pasado. Cualquier violación de las leyes internacionales, similar a todos otros tipos de violaciones, encuentran justificaciones dentro del nuevo orden internacional. Así, la sistemática y creciente confrontación Norte-Sur se justifica ideológicamente por medio del neoliberalismo económico y el neoconservadurismo religioso, los cuales contribuye a reproducir un nuevo modelo neocolonial en el Tercer Mundo. 


\section{Riqueza, Población y Pobreza}

La concentración y centralización de capitales es posible debido a que las naciones ricas e industrializadas del Norte han acumulado tecnologías avanzadas lo que les permiten depender cada vez menos del uso intensivo de recursos naturales y laborales. Debido a que el Tercer Mundo ha sido tradicionalmente productor de materias primas y un mercado atractivo para adquirir mano de obra barata, la distancia entre el Norte y el Sur ha aumentado considerablemente. Durante los últimos 30 años por ejemplo, los japoneses han sido capaces de reducir la cantidad de materias primas utilizadas en estos productos en un 33\% (Gorostiaga: 1993). Como resultado, los precios reales de las 30 materias primas principales utilizadas en la producción de ciertos artículos, las cuales se exportan desde el sur, han caído drásticamente.

Durante las décadas pasadas, las economías del Tercer Mundo han experimentado un dramático proceso de descapitalización, en donde el crecimiento del producto doméstico bruto ha declinado drásticamente, de un $6.1 \%$ anual en el período 1961 y 1973 , a un $2.8 \%$ entre 1983 y 1990. Lo mismo puede observarse con respecto al ingreso per capita, el cual cayó de un 3.3\% entre 1961 y 1970 a un $0.1 \%$ en el período 1980 y 1990 (Castro: 1993: 14).

El creciente debilitamiento de las economías de Africa, Asia, América Latina y el Caribe nos lleva a preguntarnos si es que el Norte o el Primer Mundo aún necesitan al Sur o al Tercer Mundo. En la medida que hoy día podemos observar la tendencia de que las materias primas producidas en el Sur están siendo reemplazadas por sintéticos indican que las fuerzas productivas ocupadas en dichos procesos laborales se han convertido en un elemento sobrante. Las materias primas de la región continúan siendo extraídas, pero es imposible ocupar toda la fuerza laboral disponible en dichos procesos extractivos.

Esta situación lleva a una restructuración del Tercer Mundo. Hoy día, a diferencia de lo que ocurría un siglo atrás, la mayoría de la población del Tercer Mundo es algo innecesario de acuerdo a las perspectivas económicas del Primer Mundo. Lo que aún está en demanda son los océanos, los espacios aéreos, los recursos turísticos, la energía natural y los ambientes naturales del Tercer Mundo, aunque sólo sea para utilizarlos como vertederos de residuos tóxicos industriales, químicos o atómicos. Sin embargo, estas posibilidades están totalmente sujetas al control económico, tecnológico y militar de los países del Primer Mundo.

Por estas razones el Norte no se ha retirado del Sur, prefiriendo presentarla como una región con un alto excedente de población, es decir superpoblada. Dicha sobrepoblación. contrario a lo que sucedía en el pasado, es mirada como una amenaza más que como un potencial laboral favorable de ser utilizado e incluso explotado para producir. Mientras la tasa de crecimiento de la población en los países del Primer Mundo entre 1960 y 1990 fue de un $0,8 \%$ anual, en los países del Tercer Mundo alcanzó un promedio de 2,3\% en el mismo período. A partir de 1990 hasta el año 2000 se estima que esta tasa aumentará un 2\% en lo países subdesarrollados comparada a un $0,5 \%$ en los países altamente industrializados. De continuar esta tendencia el $90 \%$ del crecimiento de la población mundial ocurrirá, entonces. en los países del Tercer Mundo (Ibíd: 16).

Así, el desarrollo tecnológico y la estructura del capitalismo moderno ya no permiten la explotación de la población excedente concentrada en el hemisferio Sur. Por lo tanto, una población que no puede ser explotada pasa a ser considerada como algo innecesario, inútil. incluso, como algo no debería ni existir. Sin embargo, aún está ahí y el nuevo capitalismo tendrá nada que ver con ella.

En este contexto, incluso el concepto mismo de explotación está cambiando. La definición clásica del concepto de explotación se refiere a una fuerza laboral disponible utilizada 
efectivamente en la producción, en donde el producto del trabajo es apropiada por el capitalista. Esta fue la tesis fundamental desarrollada por Karl Marx durante el siglo 19, expresada a través del concepto de plusvalía.

El brasilero Ruy Mauro Marini (1974), unos de los fundadores de la teoría de la dependencia, expandió la dimensión de este concepto dentro del contexto de América Latina refiriéndose a la superexplotación del trabajo. Marini demostró que la fuerza laboral latinoamericana estaba expuesta a un sistema más intenso de explotación al reducirse la parte del trabajo social necesario cancelado a los trabajadores por los empresarios. Jaime Osorio (1979) basado en las formulaciones de Marini estudió los efectos de la superexplotación del trabajo en México, mientras que André Gunther Frank, otro pionero de los estudios de la dependencia, lo hizo extensivo al Tercer Mundo.

Hoy día, sin embargo, la situación es tal que la población del Tercer Mundo no puede ser utilizada en su totalidad para la producción capitalista, como tampoco existen las intensiones o las posibilidades de hacerlo en el futuro. Así, entonces, un mundo está emergiendo en donde el ser explotado, e incluso superexplotado, resulta un privilegio. Mientras más innecesaria se considera a la población laboral de una sociedad la noción de explotación y superexplotación adquieren una cada vez menor significación e importancia, incluso en la conciencia misma de los trabajadores. En efecto, los trabajadores tienden a sentirse menos explotados cuando entienden que son más privilegiados que aquellos considerado como innecesarios o superfluos en el proceso productivo. Este ejército de mano de obra dispensable no pueden ir a la huelga, tampoco tienen ninguna capacidad negociadora, y sus amenazas no tienen significado alguno.

El Primer Mundo necesita a las naciones del Tercer Mundo, pero no a sus poblaciones. Este fenómeno coincide con la transnacionalización de los sistemas de producción, financiamiento y mercado, los cuales, por primera vez, permiten la creación de un mercado global. En 1990, la Naciones Unidas estimaban que existían 1.200 millones de personas viviendo bajo los nivel de pobreza en el Tercer Mundo. Por ejemplo, la tasa de exportación de América Latina en el mercado mundial cayó de un 12,4\% en 1980, a un 3,9\% en 1990 (Glyn y Sutcliffe: 1992: 90). Las inversiones extranjeras declinaron de un 12.,3\% a un 5,8\% entre 1980 y 1989. Como resultado, el número de personas que viven en la pobreza en América Latina ha aumentado de 112 a 184 millones solamente en una década; esto es, el 44\% del total de la población (Gorostiaga: 1993: 23).

La participación de Asia en el mercado mundial fue 13,1\% en 1950, aumentó a 17,8\% en 1980 para volver a declinar a un 14.0\% nuevamente en 1990. El caso de Africa es más impresionante. En 1950 alcanzó un 5,2\%, en 1980 cayó a 4,7\%, alcanzado un 1,9\% solamente en 1990 (Glyn y Sutcliffe: 1993: 91). El efecto de esta situación a nivel mundial es desastroso lo cual contribuirá a aumentar la deferencia que existe entre el Norte y el Sur.

\section{CAMBIOS MUNDIALES AL FINAL DEL SIGLO}

Una variedad de acontecimientos internacionales ocurridos a finales de siglo veinte han influenciado drásticamente el nuevo orden mundial. Estos cambios, sin lugar a dudas, tendrán un tremendo impacto en las estructuras socio-políticas y económicas del Tercer Mundo, sus poblaciones y medio ambientes. Entre las más significativas podríamos mencionar las siguientes: desintegración del bloque socialista, la alianza europea, el bloque del Pacífico, y el declinamiento de la economía de los Estados Unidos. Analicemos estos elementos en más detalle. 


\section{Desintegración del bloque socialista}

Este evento mundial ha tenido una dramática repercusión a nivel internacional, abriendo una nueva etapa histórica en las relaciones mundiales. Sin lugar a dudas, en América Latina siempre existió una prudente cautela por parte de muchos sectores de la izquierda y otros con respecto al mundo socialista europeo, entendido como una alternativa al sistema político y económico del capitalismo. Muchos intelectuales e incluso políticos progresistas de la región insistieron en que los países de la Europa oriental nunca desarrollaron un verdadero socialismo. Más aún, se argumentaba que dichas naciones habían alcanzado el status de socialista por decreto y no a través de procesos revolucionarios, llegando incluso a formar una alianza defensiva militar después de la Segunda Guerra Mundial, durante el período de la Guerra Fría, con la Unión Soviética a la cabeza." En ese sentido, dogmatismo y modelos copiados del bloque oriental afectaron a los Partidos Comunistas de la izquierda Latino Americana y del Tercer Mundo.

Sin embargo, el colapso del bloque oriental en Europa y de la Unión Soviética ha tenido graves implicaciones para una gran cantidad de países del Tercer Mundo, especialmente aquellos que desafiaban el enorme poder y control ejercido por el Norte. Por una parte, privó a muchas naciones de recibir apoyo económico, técnico y militar por parte del bloque oriental, en donde el caso de Cuba, Mozambique, Nicaragua (hasta antes de 1990) y Vietnam (hasta 1995) constituyen un buen ejemplo de esta situación. Del mismo modo, la presencia soviética a nivel mundial contribuyó a limitar y a oponerse a los intentos imperialistas de los Estado Unidos en el Tercer Mundo y aunque de una manera más aparente que real, la Unión Soviética constituyó un constante desafío a las políticas intervencionistas norteamericanas. Así entonces, el bloque socialista con todas sus limitaciones sirvió como una muralla de contención que permitió alcanzar un balance geopolítico y como un factor de apoyo para realizar cambios importantes en el Sur. El colapso del bloque oriental, sin embargo, deja las puertas abiertas para desarrollar nuevos modelos políticos e ideológicos en el Tercer Mundo, de acuerdo a sus culturas, valores y necesidades específicas?

\section{La unificación europea}

El fin del siglo nos deja con una nueva Europa unificada ideológica, política y económicamente, un proceso el cual se desarrolló en menos de medio siglo. Esta alianza reúne a enemigos irreconciliables del pasado, tales como Alemania, Italia y España por un lado.

\footnotetext{
${ }^{6}$ Una buena indicación de esta situación son los escritos del Che Guevara y sus planteamentos acerca de los incentivos morales versus incentivos materiales. "Sobre sacrificio y dedicación." contenidos en el libro Venceremos: Escritos y Discursos del Che Guevara. La obra utilizada en este trabajo corresponde a la versión inglesa. editada por John Gerassi. The Macmillan Company. New York, 1968. Este escrito es uno de los primeros intentos de definir al hombre y a la mujer socialista en el contexto de Cuba. como a la vez, imponer los incentivos morales sobre los económicos a través de una típlea política económica testatal. También. ver el famoso discurso "Sobre el sistema presupuestario de financiamiento," en donde el Che Guevara discute las diferencias entre el sistema económico soviético (basado en incentivos materiales) y el sistema cubano que el Che consideraba más apropiada, es decir. un modelo basato en incentivos morales (Op. cit. pp. 292-316). Finalmente. ver la respuesta del Che Guevari a Charles Betteihein titulada "Planificación socialista", en el mismo trabajo citado. En esta polémica, el Che Guevara criticaba los postulados socialistas ortodoxos de Bettelheim aplicados en la Unión Soviética, basados en la definición capitalista del valor. El Che rechazaba esta definición al mismo tiempo que intentaba demostrar que tal sistema de planificación -sistema de financiamiento autónomo- se derivaba de una falta de fe en el hombre y la mujer socialista (Op. cit. pp. 401-409)

${ }^{7}$ La denominada Guerra del Golfo de 1991 en contra de Irak es un buen ejemplo del "nuevo orden mundial." Desde los primeros inicios del conflicto fue muy claro que los Estados Unidos y sus aliados europeos utilizarian la fuerza militar en vez de la negociación política o diplomática en contra del gobierno de Sadam Husscim. Más importante. esta acción militar por parte de las nacione: poderosas intentaba demostrar al resto de los países del Tereer Mundo lo que les podría ocurrir a los que intentaran desafiar sus intereses y planes. Los soviéticos, a través del gobierno de Gorbachov, optaron esta vez por sumarse a la decisión de las Nacionez: Unidas y no vetar la alternativa militar.
} 
junto al resto de las naciones europeas. Cualquiera que hubieran sido los problemas, la Unión Europea continúa moviéndose en aras de la consolidación y solidificación de dicha alianza política y económica. De esta manera, las bases para la creación de un Estado federal supranacional que asuma la responsabilidad de implementar una gran cantidad de actividades, incluyendo asuntos políticos claves, políticas externas, y defensa, continúan consolidándose aceleradamente. Las doce naciones envueltas en esta alianza visualizan al mercado europeo, formado por varios millones de consumidores, como un lugar estratégico para detener el desafío internacional representado por Japón y los Estados Unidos.

En efecto, una Europa unida podría llegar a convertirse, junto al Japón, en un centro mundial comercial y financiero. Esta situación ha comenzado a crearle algunos problemas a la hegemonía mundial ejercida hace ya un rato por los Estados Unidos, pudiendo incluso llevarnos a una nueva "esfera de influencia" a nivel mundial. Este es el desafío enfrentado por la Administración del Partido Democrático encabezada por el Presidente Bill Clinton. para evitar futuras consecuencias problemáticas para la economía de los Estados Unidos. Potencialmente, esta situación podría abrir las posibilidades para América Latina y otras naciones del Sur para tomar ventajas de la declinación del poder económico norteamericano para sus propios beneficios, a través de tratados comerciales y otros arreglos financieros.

\section{Emergencia del bloque de la cuenca del Pacífico}

Sin lugar a dudas que a finales del siglo veinte el sureste asiático y la región de la cuenca del Pacífico han emergido como poderosos centros comerciales y productivos, alrededor del poder económico del Japón. En una extensión menor, también ha emergido la asociación de los llamados Nuevos Países Industrializados del Asia del este, incluyendo la Asociación de Naciones del Sureste Asiático (ASEAN). ${ }^{8}$

Sin embargo, Japón aún no sido capaz de resolver problemas políticos y de seguridad en la región para jugar un rol correspondiente a su poderío económico. Estos asuntos no resueltos han impedido que Japón consolide un visible y cohesivo bloque similar a la Unidad Europea o al NAFTA (North American Free Trade Agreement).

La ASEAN y otras alianzas económicas de la región incluyen a aquellos países con altas tasas de crecimiento bajo la hegemonía del Japón, formando el área económica más próspera a nivel mundial. En ese sentido, esta región se ha transformado en una zona de vital importancia y atención por parte de los japoneses. Durante la década de los ochenta, casi el $70 \%$ de la ayuda oficial para programas de desarrollo proporcionada por el gobierno del Japón fue dirigida hacia los países asiáticos, un $15 \%$ al Africa, y solamente un $10 \%$ a América Latina. Del mismo modo, un gran cantidad de las exportaciones japonesas, cerca del 30\%, se canalizan hacia los países asiáticos (Itoh: 1992: 207).

A pesar de la invasión y ocupación nipona durante la Segunda Guerra Mundial y su visión imperial con respecto al Asia en el pasado, elementos comunes tales como religión y cultura, junto a fuertes sentimientos antimperialistas en contra del mundo occidental, proporcionan a Japón un ambiente favorable para llevar a cabo esta alianza económica. El elevado rendimiento económico de la economía nipona constituyen, al mismo tiempo, un poderoso imán para cimentar esta poderosa alianza entre las naciones de las regiones asiáticas. Así, en la medida que el Mercado Común Europeo y el NAFTA se extienden y fortalecen, el Japón necesita la alianza económica con Asia como una forma de escapar del aislamiento y competencia por parte del resto de sus rivales europeos y norteamericanos. Dentro de este

${ }^{8}$ Esta asociación está formada por Malasia, Tailandia, Indonesia, Brunei, Singapur y las Filipinas. 
contexto cabe preguntarse si algunas áreas del Tercer Mundo, y en nuestro caso, de América Latina pueden beneficiarse de estas actividades comerciales.

Japón es una nación pragmática. Desde el final de la Guerra Mundial, esta nación adoptó la posición de trabajar asociado con los Estados Unidos más que como un país líder independiente. Esta estrategia económica ha probado trabajar exitosamente y por lo tanto no tienen razones para cambiarla por el momento. Desde esta perspectiva, a pesar que los japoneses no son blancos ni mucho menos cristianos, la dinámica del Grupo de los Siete tiende a atraer este país dentro de la órbita del Norte. Al mismo tiempo, el Japón está consciente del control y de los intereses geopolíticos de los Estados Unidos en América Latina y otras regiones del Tercer Mundo y no tiene, por el momento, ningún interés en antagonizar a los norteamericanos. En ese sentido, la distancia entre el Norte y el Sur se acrecienta.

\section{El declinamiento del poder económico de los U.S.}

Al mismo tiempo que el Presidente George Bush proclamaba el triunfo del nuevo orden mundial después de la caída del muro de Berlín, la economía de su país estaba siendo afectada por una severa recesión. El problema principal consiste en que los Estados Unidos ha sido incapaz de controlar su déficit fiscal y comercial mientras que, al mismo tiempo, se encuentra atrapado en un enorme gasto militar.

El déficit financiero, el cual ha tenido un profundo impacto en el país, ha generado un enorme endeudamiento de su economía. El periódico Financial Times del 10 de Julio de 1991, indicaba que la deuda pública había alcanzado la astronómica suma de 300 mil millones de dólares a finales de 1989. El dólar, una moneda tradicionalmente utilizada como fuente de reserva internacional, ha perdido gradualmente su status preferencial cayendo de un $78,4 \%$ al comienzo de 1973 , a un $56 \%$ a finales de 1990 . Durante el mismo período, por el contrario, la participación del marco alemán aumentó de un $5.5 \%$ a un $19,7 \%$, mientras que la del yen japonés aumentó de cero a 9,1\% (Glyn \& Sutclife: 1992: 91).

Por otra parte, los Estados Unidos han perdido su competitividad tecnológica y productividad, debilitando las posibilidades de mantener su hegemonía mundial a menos que continúe utilizando su poderoso aparato militar e ideológico. En efecto, dicha hegemonía ha sido posible a través de invertir 300 mil millones de dólares al año en armamentos, y a su capacidad de controlar dos tercios de los medios de comunicaciones de masas del planeta. Sin embargo, debido a la aguda crisis económica que atraviesa este país, la administración del Presidente Clinton se vio forzada a reconsiderar sus políticas internacionales y dominio militar, llevándolo gradualmente a abandonar parte de su modelo neo-imperialista. Lo mismo puede observarse en la instituciones financieras en las cuales los Estados Unidos han ganado hegemonía económica tales como el Banco Interamericano de Desarrollo, el Banco Mundial, el GATT, y la Organización para la Cooperación Económica y Desarrollo. Esta no es una decisión voluntaria y los Estados Unidos está aún intentando mantener su posición dominante, la cual se encuentra actualmente desafiada por sus aliados, y a la vez, competidores europeos y japoneses.

El sistema de explotación impuesto en el Tercer Mundo también se ha expandido al Primer Mundo, afectando a los Estados Unidos mismos, como al resto de las regiones del Norte, incluyendo ahora a Europa del este. Actualmente no existe un sistema explotativo diferente para los Estados Unidos y el resto de las Américas y el Caribe. La búsqueda de mano de obra barata, materias primas y mercados ha sobrepasado las fronteras internacionales. Hace ya un rato que la industrias norteamericanas comenzaron a ser transferidas hacia 
América Latina y otras regiones provocando despidos masivos y una alta cesantía entre su población, la cual también ha sufrido la eliminación de servicios sociales tanto a nivel estatal como federal, y en donde la pobreza se expande a través de toda la nación. Durante los últimos 15 años, el ingreso del $5 \%$ de los sectores más pudientes de este país ha aumentado 50 veces, mientras que las entradas del $60 \%$ de los sectores más bajo de la población han visto sus ingresos reducidos significativamente. Actualmente, uno de cada cinco niños vive en los niveles de pobreza (Burbach: 1992: 240). Del mismo modo, es muy frecuente encontrar hoy día en las entradas de los modernos shopping centers o malls de los Estados Unidos, a grupos de individuos con letreros solicitando trabajo a cambio de alimentos (work for food). ${ }^{9}$

Sin lugar a dudas, el nuevo orden económico mundial está afectado severamente a la economía de los Estados Unidos. A pesar de que no es aventurado afirmar que una nueva etapa histórica se ha iniciado no sólo por el colapso del socialismo histórico y la Unión Soviética, el futuro no se ve muy promisorio para el Sur y para un amplio sector de la población de los Estados Unidos y Canadá.

\section{EL MODELO NEOLIBERAL}

El modelo neoliberal actual promueve, fundamentalmente, la total libertad de movimientos de capitales, bienes y servicios, junto a una amplia apertura de las economías de las naciones y relaciones de competencia en el mercado mundial, dentro de una absoluta independencia. En contraste, la fuerza laboral es la única mercancía que no posee libertad de mercado, existiendo constantes presiones por parte del Estado para reducir su valor y costo. Dichas medidas pueden incluir desde medidas legales, pasando por la represión de los movimientos laborales, coaptación de los sindicatos y organizaciones de los trabajadores y sus líderes.

El neoliberalismo promueve enérgicamente la eliminación de las funciones reguladoras del aparato Estado, junto a la desnacionalización y privatización de sus bienes y servicios. En otras palabras, en vez de utilizar al Estado, tal como ocurría en el pasado, este modelo económico promueve que sea el mercado el encargado de determinar el crecimiento de la producción, distribución, renovación tecnológica, e incluso, las necesidades sociales. Aquí, el problema principal es que una vez que se reduce y debilita el rol del Estado, se disminuye la capacidad de la economía nacional para detener y confrontar las presiones financieras externas. Más aún, el Estado es el único mecanismo que existe en una nación que puede crear las instancias necesarias para suavizar los efectos de las presiones, las crisis internacionales y otros problemas similares.

Para aliviar las consecuencias sociales negativas del modelo neoliberal, los promotores de este sistema económico han eliminado ciertos espacios tales como la negociación colectiva de los conflictos laborales, favorecido el crecimiento de la economía informal, y la puesta en marcha de algunos programas de asistencia social, los cuales tienen un efecto más propagandístico que reales, tales como la extensión de pagos de cesantía y bienestar social (en el caso de las naciones desarrolladas) y la creación programas de empleo mínimo, en el

\footnotetext{
"En diciembre de 1991, la General Motors anunció que procedería a clausurar 21 plantas y a despedir a 74.000 trabajadores como resultado de una pérdida de 4.5 mil millones de dólares durante ese año. En ese mismo período. 50.000 empleos fueron eliminados en el municipio de los Angeles. haciendo que la tasa de desempleo aumentara de 6,1\% a 9.3\% (Milliband y Panitch: 1992:7).

En octubre de 1991, el número de norteamericanos recibiendo ayuda a través de programas alimenticios (Food Stamps) alcanzaban a 24 millones de personas, es decir, el 9,6\% de la población. Once meses antes, las mismas estadísticas indicaban que solamente 3,2 millones de individuos estaban acogidos a este plan de ayuda alimenticia.
} 
caso de algunos países de América Latina.

El discurso neoliberal acentúa la ideología que pregona la incapacidad del Estado como administrador y empresario, junto a una serie de nociones, interpretaciones, y principios esgrimidos para promocionar dicho modelo económico. Entre estas nociones y principios elevados a la categoría de dogmas universales por parte de los neoliberales, se pueden mencionar la competencia, una fuerte disciplina laboral, pragmatismo, y el reemplazo de las agrupaciones sociales de masas por grupos pequeños o individuos, como los agentes intermediarios e interlocutores principales en la sociedad.

Los proponentes del neoliberalismo también enfatizan que la reorganización de la economía mundial de acuerdo a los nuevos intereses y necesidades del capitalismo y las corporaciones multinacionales, son el resultado de la evolución histórica de las sociedades. Más importante, esta evolución histórica se presenta como un proceso al cual todas las naciones tienen que unirse inevitablemente. De este modo, esta lógica se utiliza para justificar la desnacionalización de los Estados de América Latina como parte del costo que la región debe pagar para integrarse al "nuevo orden económico mundial". Repitamos, lo anterior se refuerza con la caída del bloque socialista y el desmantelamiento de la Unión Soviética.

Finalmente, de acuerdo al modelo neoliberal, el concepto de soberanía, desarrollo. justicia social y democracia, también han sido redefinidos. Desarrollo, por ejemplo, se describe como una meta que todos los países pueden alcanzar si estos se unen al proceso neoliberal, el cual se presenta como una etapa que requiere "tiempo y sacrificio". Así, la justicia social se define como una función de las oportunidades creadas por el esfuerzoindividual de las personas, mientras que la democracia es un valor universal sin un contenido de clase o calificaciones políticas de izquierda y derecha.

\section{EL MODELO NEOLIBERAL LATINOAMERICANO}

La implementación de los modelos neoliberales en América Latina muestran tres etapas muy claras. El primer período, iniciado cerca de los finales de la década de los sesenta, cuando las economías de la región había promovido la implementación de los procesos desarrollistas de industrialización, basados en un proteccionismo de Estado. A pesar que algunos neoliberales durante ese período no formularon políticas bien pensadas y racionales, los precursores de este modelo criticaron "la apertura" de las economías de América Latina. Al mismo tiempo, sus proponentes sostenían que la estagnación que afectaba la industrialización de ciertos países era el resultado de la ineficiencia, principalmente del Estado, el cual se ha caracterizado históricamente por ser un pésimo administrador. Los neoliberales atribuían básicamente esta falta de eficiencia por parte del Estado a la carencia de competencia externa, y en donde la inflación se atribuía a los esfuerzos de los gobiernos regionales para estimular el empleo y el crecimiento económico. ${ }^{10} \mathrm{~A}$ mediados de los setenta, la tendencia para abrir las economías regionales a los inversiones y créditos extranjeros se acentuaron. El modelo del economista Milton Friedman junto a sus seguidores, más co-

\footnotetext{
${ }^{10}$ Estas "aberturas" en las economías Latinoamericanas no fueron aplicadas a todos los páses de la región. En cfecto. el desarrollo del proceso de industrialización siguió diferentes procesos en el continente. Paises tales como Argentina. Brasil. Colombia. Chile. Uruguay y México comenzaron dicho proceso a finales del siglo diecinueve como resultado de diferentes situaciones. Durante los periodos que van entre las dos Guerras Mundiales, este proceso de industrialización se intensificó en los seis países mencionados bajo el alero del Estado, financiado con capitales nacionales. Otro grupo de naciones. Perí y Venezuela. promovieron el proceso industrial después de la Segunda Guerra Mundial, pero bajo la iniciativa directa del capital extranjero. Las naciones centroamericanas Ecuador, Paraguay y Bolivia en Sud América, sólo comenzaron la industrialización a partir de los sesenta, también bajo el contro directo del capital extranjero, promovido por los gobiernos locales y la Alianza para el Progreso del Presidente Kennedy. Para mayor detalles de los procesos de industrialización en América Latina ver el trabajo de Vania Bambirra. El capiralismo dependiente latinoamericano. (Siglo XXI: México: 1973).
} 
nocidos como los Chicago boys y sus políticas neoliberales, comenzaron a predominar en América Latina.

Durante la segunda etapa, este modelo neoliberal se aplicó en una forma radical en varios países. Sin embargo, como una precondición a su aplicación, fue necesario llevar a cabo una serie de golpes de estados orientados a la instalación de dictaduras militares para que se hicieran cargo del Estado (Vasconi: 1974). Este fue el caso de Brasil en 1964 y 1968 , Argentina en 1966, Chile en 1973, Argentina y Uruguay en 1976. En países como Chile, por ejemplo, la economía se abrió totalmente a los capitales y servicios extranjeros. El rol del Estado, entendido como un regulador económico y benefactor social, tal como ocurría en el pasado, fue rápidamente eliminado.

Al final del período de los regímenes militares que controlaron la región entre 1964 y 1990, los nuevos gobiernos civiles que asumieron se encontraron totalmente atrapados por una enorme deuda externa. Los gobiernos del Cono Sur intentaron aplicar algunos fórmulas social-demócratas como modelo económico, desarrolladas por Comisión Económica para América Latina, más conocida como la CEPAL, en parte porque el neoliberalismo estaba demasiado asociado con los militares, pero también, debido al temor de que los efectos negativos de este modelo económico podrían afectar sus pretensiones electorales. A esto debemos agregarle, el temor de algunas de las nuevas autoridades civiles de poder sobrevivircon sus frágiles gobiemos democráticos debido a la continua presión de los militares y sus asociados, el gran capital nacional y extranjero.

La transición de los regímenes militares a regímenes electorales civiles se asoció rápidamente con "democratización". La realidad, sin embargo, vino a demostrar que esto fue sólo un cambio de régimen que no alteró o desafió el poder de las instituciones más críticas del Estado tales como las Fuerzas Armadas, los servicios de inteligencia, los servicios civiles, los bancos centrales y el poder judicial. También se hizo evidente que mientras los militares habían retornado el gobiemo a los civiles, las fuerzas armadas retenían un significativo poder de veto sobre el proceso de "redemocratización". Los crímenes de lesa majestad, la violación de los derechos humanos, la situación de los miles de desaparecidos y asesinados por las militares, la corrupción y otros hechos importantes fueron silenciados y cubiertos por la impunidad. Las nuevas autoridades civiles elegidas decidieron abandonar estas controversiales materias, concentrándose en la protección y promoción del modelo neoliberal puesto en práctica por las fuerzas armadas.

La tercera etapa del modelo neoliberal se desarrolló con la crisis ocurrida durante la década del ochenta, cuando la profundización de la deuda externa forzó a muchos países de la región a abandonar sus experimentos social demócratas. Al respecto, dos elementos pueden señalarse para explicar esta tendencia. En primer lugar, los gobiernos civiles no pudieron crear un modelo que les permitiera esparcir adecuadamente el creciente costo de los ajustes económicos. En segundo lugar, los países de América Latina experimentaron un enorme presión en sus economías por parte del capital extranjero, a través de la deuda externa. Como resultado, al final de los ochenta y comienzo de los noventa, el modelo neoliberal se consolidó en América Latina. De acuerdo a Petras y Morley (1992: 13), durante este período el Producto Doméstico Bruto cayó más de un 8\%. Países como Argentina, Bolivia, Perú y Venezuela, por su parte, experimentaron caídas entre un 24 y un $26 \%$ (Ibíd).

El origen de la crisis de la década de los ochenta que permitió la consolidación del modelo neoliberal en América Latina requiere alguna atención. A partir de los cincuenta hasta los ochenta, la masiva afluencia de capital extranjero transnacional produjo un crecj-

${ }^{11}$ Para un análisis más detallado del Estado Militar, ver el trabajo de Tomás A. Vasconi. Gran capital y militariziución en América Latina. (México: Editorial ERA, 1978) 
miento promedio anual de 5\% (Sánchez-Otero: 1993: 19). Como resultado de esta expansión económica dependiente, las economías de América Latina se insertaron dentro del marco general del capitalismo imperante en esa época y las industrias de la región y sus modelos de substitución de importaciones perdieron su carácter nacional. Ciertas áreas del sector agrario también se adecuaron para alcanzar el mercado internacional, pero lo más importante fue que los sectores más críticos de las economías regionales pasaron a ser controladas por capitales extranjeros, produciendo una casi total subordinación en áreas como las ciencias y la tecnología.

La resistencia interna por parte de algunos sectores y gobiernos nacionalistas y populistas --bajo el liderazgo de la burguesía industrial-- los cuales se habían originado durante las primeras décadas del siglo diecinueve, fracasaron en sus intentos de proteger sus proyectos económicos. Dichos modelos fueron, entonces, rápidamente dejados de por lado y la burguesía abandonó sus esfuerzos originales de resistencia para terminar finalmente uniéndose a los inversionistas extranjeros y convertirse en sus asociados menores.

Los gobiernos de América Latina y el Caribe comenzaron a solicitar créditos extranjeros, los cuales, a partir de los setenta estuvieron rápidamente disponibles para palear los efectos negativos de esta nueva subordinación al capital internacional. Por medio de estos créditos extranjeros, los gobiernos de la región intentaron resolver el problema del deterioro de los términos comerciales, el sobreprecio del valor del dólar, la fuga de capitales, la carencia de ingresos para financiar las necesidades básicas del Estado y otros efectos de la transnacionalización. Las inyecciones de dinero obtenido a través de préstamos en el extranjero significaron que varios gobiernos pudieron continuar apoyando sus complejos industriales y sus correspondientes modelos de sustitución de importaciones por un rato, aunque igualmente terminaron atrapados por las agencias crediticias y el capital foráneo. Sin embargo, los complicados y perniciosos mecanismos de la deuda externa vinieron a agravar esta crisis al final de los setenta, continuando durante los ochenta. ${ }^{12}$

Concluyendo, el nuevo orden económico mundial, bajo la hegemonía del Grupo de los Siete, ha acrecentado la crisis no sólo en América Latina sino que, también, en el Tercer Mundo a través de imponer a las naciones deudoras del Sur la implementación de ajuste económicos extremadamente pesados y onerosos para sus poblaciones. Dichas medidas draconianas por parte del Norte tienen como función principal asegurar la cancelación de la enorme deuda externa acumulada por el Sur. Sin embargo, esta estrategia también apunta a apoderarse de los abundantes recursos naturales, bienes y servicios del Tercer Mundo en compensación por la reducción de sus deudas externas, especialmente cuando cada vez es más evidente para el Primer Mundo la imposibilidad real que las empobrecidas y subdesarolladas naciones del Sur enfrentan para continuar canalizando sus capitales líquidos hacia el Norte.

\section{CONSECUENCIAS DEL NEOLIBERALISMO}

Los efectos del neoliberalismo en la mayoría de los países de América Latina ha sido. sin lugar a dudas, desastrosos, cuyas característica principales se expresan a través de li privatización y el control extranjero de sus economías. En efecto, la región se encuentra er. medio de un profundo y acelerado proceso de restructuración económica y apropiación de

\footnotetext{
${ }^{12}$ Acerca de los mecanismos que generan la deuda externa ver el capitulo III de nuestro trabajo The Bridge Berween Canadi: Latin America (con Mario Lee). También La cancelación de la deuda externa y el nuevo orden écomómico, de Fidel Castro, public.. en la Habana en 1985.
} 
sus sistemas productivos. En México, por ejemplo, de 1050 empresas estatales en 1983 , únicamente 285 permanecían como tales en 1990 (Teichman: 1993). Al término del período presidencial de Salinas de Gortari en 1994, México conservaba prácticamente ninguna industria estatal significativa. Un poco más tarde, el gobierno mexicano completó el proceso de reprivatización de todos los bancos nacionalizados en 1982.

Tan pronto el Presidente Salinas de Gortari tomó el poder, su gobierno comenzó a abrir rápidamente la economía de su país a los inversionistas extranjeros. En mayo de 1989, las leyes mexicanas fueron modificadas para permitir la operación de corporaciones foráneas y la entrada de capitales internacionales en las áreas controladas por el Estado. En junio del mismo año 1989, el Presidente Salinas de Gortari inició conversaciones informales con el Presidente George Bush y el Primer Ministro canadiense Bryan Malroney para establecer un tratado de libre comercio. Mientras el gobierno mexicano ofrecía abolir prácticamente la mayoría de sus tarifas aduaneras y restricciones para los inversionistas extranjeros, al mismo tiempo se preparaba para vender el poderoso sector de comunicaciones controlado por el Estado, Teléfonos de México, junto a un paquete de otras empresas públicas. La intención del gobierno era recolectar 20 mil millones de dólares a la brevedad posible (Lederma: 1990: 1).

El caso de Argentina también es significativo. A mitad del año 1989, el gobierno justicialista del Presidente Menem, un socialdemócrata convertido al neoliberalismo, se embarcó en un agresivo plan de privatización y medidas de austeridad orientados a renovar la economía de su país. Durante ese período, importantes industrias estatales en el área de las comunicaciones y el transporte fueron vendidas a corporaciones multinacionales europeas y norteamericanas. Del mismo modo, $60 \%$ de la poderosa compañía estatal de teléfono fue adquirida por dos consorcios, uno europeo y el otro de los Estados Únidos. De acuerdo a Petras y Morley (1992: 54), de un total de 2,3 millones de obreros en Argentina, un millón de ellos perdieron sus empleos entre los meses de octubre de 1989 y octubre de 1990.

De acuerdo a los estándares utilizados en los países desarrollados, las industrias caracterizadas por una baja productividad y tecnología anticuada en manos de pequeños y medianos propietarios, han sido eliminadas y sus productos reemplazados por artículos importados.

La rápida apertura de las economías regionales al capital extranjero responden a las necesidades inmediatas de generar ingresos para servir su enorme deuda externa. Sin embargo, esta situación ha significado prácticamente desmantelar el Estado, lo cual, junto a las privatización de las empresas estatales y los drásticos cortes al presupuesto de la nación, han originado un alarmante incremento de la cesantía y un alarmante crecimiento de los niveles de pobrezas de una manera nunca antes observados en ese país.

Chile, uno de los más orgullosos ejemplos del modelo neoliberal, en 1969, es decir cuatro años antes del golpe militar que derrocara al Presidente Salvador Allende, 28,5\% de la población vivía en la pobreza. En 1979, después de seis años de gobierno militar, el nivel de pobreza había aumentado a 36\%, llegando a 42\% en 1989 (Ruiz Tagle: 1991: 46).

En Costa Rica, el porcentaje de la población que vive bajo los límites de pobreza, también ha aumentado dramáticamente en sólo cinco años: desde un 18,6\% en 1987 a 24,4\% en 1991. Del mismo modo se estima que alrededor del 37\% de los trabajadores recibían salarios inferiores al mínimo requerido por la ley (Inforpress: 1992: 6).

En el caso de México, la tasa de cesantía es de alrededor del $20 \%$ mientras que el subempleo es casi el doble (Escobar: 1991: 9). El crecimiento del sector informal de la economía-individuos subempleados y pequeñas empresas- creció un $80 \%$ durante la década de los ochenta, lo que constituye un indicador significativo de la inestabilidad que caracteri- 
za el modelo neoliberal mexicano y su inhabilidad para crear empleos suficientes.

En Nicaragua, después de los dos años de estabilización y ajustes estructurales que siguieron a la derrota electoral de los sandinista (1990-1992), 53.000 nicaraguenses perdieron sus trabajos, afectando fundamentalmente al sector productivo en comparación con aquellos que laboraban en los sectores de servicios y comercio. La recesión en la producción significó la pérdida de otros 36.000 empleos en los grandes complejos agrícolas e industriales y en las empresas de la construcción. El sector más afectado por los ajustes económicos del nuevo modelo neoliberal fue el manufacturero en donde un tercio de los trabajadores (16.000 obreros) fueron despedidos durante este período (Envío: Marzo de 1993: 19-20).

La Iglesia latinoamericana también ha decidido hacerse presente en el debate acerca del neoliberalismo y sus efectos en la población. El Obispo de Chimbote, Perú, Luis Armando Bambarón, en un mitin del Consejo Episcopal Latinoamericano (CELAM) sostenía que en su país la privatización de las compañías públicas y la reducción de la oportunidad se tradujeron en despido masivo de 500.000 empleados. Más aún, de acuerdo al prelado, sólo el 7\% de la población laboral recibe un salario justo, "debido a que el neoliberalismo está sólo preocupado de la eficiencia, haciendo al éxito económico más importante que los seres humanos, y en donde el pueblo paga por sus errores" (L. P.: 8 de abril de 1993; p. 1).

El Arzobispo de Cali, Colombia, Pedro Rubiano, agregaba a lo sostenido por el Obispo Bambarón que el neoliberalismo latinoamericano "ha permeado todos los países como resultado de una realidad común. A pesar que este modelo tiene algunos aspectos positivos. los costos sociales son muy altos, incluyendo la tremenda separación entre pobres y ricos, la cual en vez de disminuir está siendo cada vez más amplia" (Ibíd.).

La preocupación de los obispos parece ser correcta. De acuerdo a la CEPAL, en 1990 aproximadamente $44 \%$ de la población de América Latina (183 millones de personas) vivían dentro de lo que se designa como los niveles de pobreza. Esta cifra representa un aumento de 112 millones de habitantes con respecto al año 1970. Aproximadamente la mitad de este grupo, es decir 88 millones de latinoamericanos fueron señalados por el informe estar viviendo incluso bajo dichos niveles mínimos de pobreza (indigentes).

\section{EL NUEVO ORDEN MUNDIAL Y EL NEOCOLONIALISMO}

Como resultado del modelo neoliberal, los gobiemos de América Latina han sido virtualmente forzados a abandonar sus esfuerzos para alcanzar plena soberanía nacional y un verdadero desarrollo económico. A partir de la independencia, nunca antes las políticas gubernamentales de la región fueron controladas y manejadas tan directamente por agencias extranjeras como los son hoy día, a través del BID, el Banco Mundial y otras organizacione: crediticias internacionales. En ese sentido, el neoliberalismo se haconvertido en sinónimo de neocolonialismo tanto en América Latina como en el Caribe, cuyos únicos beneficiarios han sido las corporaciones transnacionales y sus aliados regionales: un grupo reducido de las clases dominantes de cada uno de esos países.

Políticas con respecto a ajustes estructurales han sido masivamente adoptadas por lo. nuevos "regímenes electorales" de América Latina y del Caribe. En gran medida, estas políticas han sido el resultado de severas presiones por parte de agencias crediticias extranjeras. las cuales han jugado un importante rol en las procesos intemos de los países de la región. Estas agencias que incluyen al BID, al Banco Mundial, al Fondo Monetario Internacional. el Chemical Bank, están todas conectadas con gobiernos, bancos privados y grupos que actúan como intermediarios del Norte, ${ }^{13}$ las cuales ejercen un enorme control de las economías: 
gobiernos de los países de América Latina y el Caribe. La mayoría de dichas políticas precluden a los organismos nacionales, una situación que reduce las posibilidades de autodeterminación, legitimidad de los regímenes políticos y autonomía para desarrollar e imponer sus propias opciones. ${ }^{14}$

Muy pocos disputarán que la legitimación doméstica de un gobierno y sus autoridades oficiales, programas políticos, e instituciones públicas se encuentran generalmente limitadas a menos que ese gobierno pueda mejorar los niveles de servicios que proporciona a sus ciudadanos. Este no es el caso de las sociedades de América Latina las cuales nada pueden hacer por sus poblaciones cuando cuentan con reducidos ingresos y un subdesarrollo crónico. La aplicación de políticas que contemplan ajustes estructurales intolerables tales como reducción de impuestos a las corporaciones, reducción de la barreras proteccionistas, eliminación de subsidios y privatización de las empresas públicas, especialmente las más rentables, conducen a la transferencia y acumulación de riquezas en las manos de una pequeña élite doméstica y sus asociados internacionales.

En Chile, por ejemplo, la tasa de ingreso del 20\% más rico de la población en 1969 era $44,5 \%$, comparado con $7,6 \%$ del $20 \%$ más pobre de los chilenos. En 1988 , el radio entre ambos sectores sociales de este país fue de $54.6 \%$ y $4.4 \%$, respectivamente (Ruiz Tagle: 1992: 46). Entre 1982 y 1989, la remisión de utilidades y pagos de intereses a las corporaciones multinacionales y bancos totalizaron 281,5 mil millones de dólares.

De acuerdo al Times of the Americas (10 de enero de 1990, p. 3), una vez deducidos los nuevos préstamos e inversiones, América Latina continua siendo un exportador neto de capitales, los que estiman en 200 mil millones de dólares. En este sentido, la intensidad de las presiones externas y apoyo a este modelo económico aumentan mientras que, al mismo tiempo, se reduce el apoyo intemo de la economía, una situación que se traduce en cortes y debilitamiento de la educación, programas de salud, bienestar social y servicios públicos. Como resultado, se produce una creciente alienación de los sectores populares, originando descontento y mobilizaciones sociales las cuales abren las puertas a nuevas estrategias disidentes para resistir dichas medidas. De esta manera, la credibilidad de las estructuras políticas y sus autoridades comienzan a ser severamente cuestionadas a pesar de los esfuerzo de la prensa oficialista para continuar promoviendo el modelo neoliberal. Lo anterior se refuerza a través de las discrepancias que emergen entre la retórica de la legitimación de los regímenes locales y la implementación de los programas políticos y económicos de las élites locales.

Confrontados con los desafíos al mito político del neoliberalismo de la región y la creciente oposición popular de los sectores más postergados, las clases dominantes deben recurrir al viejo truco de la represión. Sin embargo, entre más dependiente se transforma un Estado del uso de la fuerza, más se debilita en términos políticos y económicos. A pesar de esta antigua verdad, para mantener la estabilidad socioeconómica en los países de América Latina es necesario imponer la inestabilidad política, una situación que deslegitima a los denominados gobiernos "democráticos" elegidos después del retorno de los militares a sus cuarteles. Esto también viene a demostrar que la "democratización" política y socio-económica no pueden reconciliarse dentro del desarrollo dependiente expresado a través de la

\footnotetext{
${ }^{3}$ Para una discusión acerca de los vínculos de los grupos internos y externos gue afectan las políticas de desarrolloy los procesos de América Latira, ver el trabajo de Douglas Chalmers. "Developing in the Periphery: External Factors in Latin American Politics. en Power and Social Control Social Structures and their Transfonmation. ediado por Tom Burns and Walter Buckley en 1976.

${ }^{H}$ El Banco Interamericano de Desarrollo (BID), por ejemplo. es una organización financiera internacional ubicada en Washington D C desde 1059. El BID cuenta con 28 países miembros del heinislerio occidental y 17 fuera de la región. En todos sus años de operación, el BID ha proporcionado 159 mil millones de dólares en préstamos a diferentes proyectos del Tercer Mundo. Esto organismo cuenta con oficinas regionales en América Latina y el Caribe para relacionarse con las autoridades locales y supervisar las fórmulas y proyectos patrocinados por el BID.
} 
política de los ajustes estructurales aplicados en América Latina y el Caribe.

Esta realidad fuerza a los gobiernos regionales a enfrentar severas contradicciones respecto a la bonanza neoliberal y los efectos en sus poblaciones respectivas. En primer lugar, cuestiona la noción de que los profundos cambios sociales que se originan en la sociedad pueden ser "arbitrados" y resueltos a través de los mecanismos propuesto por las "democracias electoralistas" en sociedades dependientes y subdesarrolladas. En segundo lugar, la idea de que el Estado es un mecanismo neutro en la sociedad, cuyas situaciones y demandas conflictivas pueden ser "arbitradas", pierden credibilidad entre las clases sociales que forman dichas sociedades. ${ }^{15}$ En ese sentido, como un tercer aspecto, la creencia de que los cambios de la actual estructura socio-económica de las sociedades de América Latina pueden lograrse sin alterar el rol del Estado, se convierte en una materia altamente cuestionable. Finalmente, el modelo neoliberal implantado en América Latina y el Caribe constituye un serio desafío a la noción de que un Estado nacional es el encargado del bien común de la nación demostrando, por el contrario, que estos operan como mecanismos que mantienen la naturaleza dependiente y el subdesarrollo de esas naciones, una situación que sólo beneficia al gran capital nacional y extranjero.

\section{El sector informal}

El neoliberalismo produce neo-marginalidad, eufemísticamente designado como el "sector informal de la economía", compuesto por vendedores callejeros de diferentes artículos, incluyendo jugos y comidas, lustrabotas, cuidadores de automóviles, acarreadores de bultos, músicos y artistas callejeros, etc. En realidad, este sector de la economía es uno de los efectos más prominente y pernicioso del modelo neoliberal tanto en sus dimensiones humanas como económicas, políticas e ideológicas. Dentro de esta reconceptualización neoliberal de la marginalidad las soluciones privadas y familiares han venido a reemplazar a las sociales, dando lugar a una variedad de tipos de economías mezcladas y diferenciadas internamente en América Latina y el Caribe. Estas formas de economías informales han adoptado diversas características dependiendo fundamentalmente de las necesidades y nivel de oportunidades para los habitantes en sus respectivas localidades.

Una de las modalidades adoptada por estos sectores se refleja en el explosivo desarrollo de microempresas que trabajan con los grandes conglomerados o prestan servicios a! sector industrial en áreas tales como la información, la publicidad, mercado, seguridad, reparaciones y mantenimiento y limpieza. Los propietarios de estas pequeñas empresas a menudo se encuentran en los límites mismo de los niveles de pobreza, en donde los trabajadores asalariados de las mismas reciben ingresos que bordean los márgenes de subsistencia mínimos, sin beneficios sociales, ni seguridad laboral.

En el caso de Chile, por ejemplo, el sector informal emplea actualmente el $45 \%$ de la fuerza de trabajo (Van Hemeyrick: 1992: 154). El pago de bajos salarios también han forzado el ingreso de las mujeres a las diversas fuentes productivas bajo condiciones de superexplotación, las cuales en 1976, constituían el 27,6\% de la población laboral del país. aumentando al 34,6 en 1989. La mayoría de estas mujeres trabajan en los sectores má: desorganizados de la economía y que al mismo tiempo pagan los salarios más bajos. El $25^{\circ}$.

\footnotetext{
${ }^{15}$ Esta formulación política del Estado no es algo original en América Latina. En el pasado. la noción de un Estado ubicado "sčlas clases sociales" en la sociedad, cuyo rol es actuar como mediador entre los diferentes sectores sociales fue utilizado duranle regímenes populistas de Argentina (Rosas y luego Perón), Janio Cuadros y Getulio Vargas en Brasil. Pedro Aguirre Cerda y I $\ldots$. Antonio Ríos en Chile. Esta forma de Estado corresponde a la noción "bonapartista" del mismo. analizada extensivamente por $h$ Marx en su obra clásica, El dieciocho de Brumario.
} 
de estas mujeres, por ejemplo, se desempeñan como sirvientas domésticas. Del mismo modo, las nuevas oportunidades de empleos temporales en la agricultura son llenadas con mujeres las cuales trabajan durante los períodos de cosechas y recolección de frutas, contratadas por salarios mínimos y con prohibición absoluta de organizarse para negociar sus condiciones laborales y valor del trabajo. ${ }^{16}$

En Costa Rica, ciertas fuentes indican que entre 1980 y 1990 la expansión del sector informal de la fuerza de trabajo urbano aumentó del 14 al 22\% (Latin America Weekly Report: Octubre 29, 1992). Después de mantenerse prácticamente constante, alrededor de $17 \%$ entre 1980 y 1986 , la categoría "empleado por cuenta propia" dio un salto alcanzado un $22,9 \%$ en 1987 y un $24,8 \%$ en 1991 . Sin embargo, el $53 \%$ de esos trabajadores independientes se ubicaban bajo los niveles mínimos de pobreza en 1991, mientras que sólo el 39,8\% de los trabajadores asalariados de ese país escapaban de esa clasificación (CEPAS: 41-49).

En México, la economía informal creció un $80 \%$ durante la década de los ochenta (Escobar: 1991:9). A través de los parques industriales, créditos y facilidades administrativas, el gobierno de ese país promovió entre los comerciantes marginales y los "empresarios informales" a integrar sus actividades con las grandes corporaciones multinacionales, especialmente a través del sistema de las maquiladoras.

El modelo neoliberal también ha creado un tipo de economía popular traducida en la creación de pequeños talleres, negocios familiares, industrias caseras, o pequeños negocios, con tres o cuatro asociados, tales como pequeñas amasanderías, cocinerías, artesanías, tiendas y almacenes pequeños, restaurantes, café, bares, etc. Este tipo de actividades económicas operan alrededor de un dueño de casa, frecuentemente con la colaboración de la familia. Dependiendo de sus resultados operacionales, estos pequeños negocios pueden llegar a transformarse en microempresas, crear unos pocos trabajos más, y producir algunas utilidades para los municipios, estados o provincias, via impuestos.

Otra expresión económica desarrollada a partir del neoliberalismo es la formación de organizaciones populares económicas consistentes en grupos pequeños en un barrio, grupo vecinal u organización que recurren a formas colectivas para resolver las necesidades y problemas sociales, económicos, legales y culturales más inmediatos. Así, es posible observar la masificación de ollas comunes, comedores populares, formación de cooperativa para comprar o vender alimentos, cooperativas de artesanos, clínicas legales, etc, para resolver los problemas de los sectores más postergados de la población. Otras iniciativas han consistido en programas de entrenamiento auspiciados por organizaciones de iglesias y agencias no gubernamentales (ONGs) como, por ejemplo, grupos de salud, comités de construcción de viviendas, comités de obreros cesantes, etc.

Las iniciativas individuales denominadas como informales incluyen actividades tales como vendedores callejeros, servicios domésticos -limpiadores de ventanas, jardineros, aseadores de casas, recolectores de basuras, músicos callejeros, cuidadores de automóviles, y muchos otros tipos de oficios similares. Estas actividades sirven para complementar algunos vacíos del mercado, aunque, sin embargo, la mayoría de las veces son el resultado de la

\footnotetext{
"En su edición del 4 de abril de 1993, el New York Time informaba cntusiastamente que cl Gobieno de Chile estaba exhblendo un éxito singular en el desarrollo de programas orientados hacia los negocios pequenos que confoman lit economa informal. Sir embargo, este periódico norteamericano sostenía que estas "compañas no registradas, que no pagan impuestos. son sorprendentemente productivas, con pocas probabilidades de expandirse. fundamentalmente. porque no tienen acceso al crédilo." El mismo periódico reconocía que en estas "empresas" trabajan menos de cinco personas y son críticas para la cconomía del país ya que emplean el $40 \%$ de la fuerza laboral y al $80 \%$ de los sectores más pobres del país.

Cualquiera que sean estos programas. Ia realidad es que un importante sector de la fuerza laboral chitena no tienen aceeso a un empleo decente para subsistir. La referencia del periódico norteamericano acerca de las "empresas" intormales que no pagan impuesto, sino fuera tan cruel resultaría bastante risible. Pareciera ser que el New York Time al aplaudir tan acaloradamente al gobicrno chileno estuvicra promoviendo un impuesto público a la pobreza para seguir privatizando las empresas públicas y financiar a las fuerzas armadas y policiales que reprimen a los pobres del pás cuando estos demandan empleos y salarios dignios.
} 
increíble creatividad de los sectores empobrecidos para originar actividades laborales que les permitan generar ingresos para sobrevivir y subsistir. Algunas veces, estas actividades empresariales populares pueden operar vinculadas a empresas formales e incluso corporaciones, cumpliendo funciones auxiliares que dichas empresas no quieren llevar a cabo para de, esta forma, eludir el pago de beneficios legales a sus trabajadores e impuestos a las municipalidades o gobiernos. Esta fórmula constituye otra forma de acceso a mano de obra barata y un mecanismo para estimular e incrementar la tasa de ganancia por parte de las grandes empresas.

Otras iniciativas de sobrevivencia también han sido desarrolladas por ciertos sectores de la población para palear los efectos del modelo neoliberal. Estas varían desde subsidios estatales a los indigentes hasta pedir limosnas en las calles. Como resultado, los sectores más empobrecidos cuentan con muy pocas oportunidades económicos debiendo, por lo tanto conformarse con sobrevivir forzadamente dentro de espacios muy reducidos, incluyendo acciones delictivas como hurtos, e incluso acciones violentas tales como asaltos y robos a mano armada. Las actividades que se realizan fuera de la ley han aumentado notoriamente. especialmente alrededor de los centros urbanos más densamente poblados de América Latina y el Caribe. Las zonas marginales de estas regiones se han transformado en lugares con altas tasa de criminalidad, niveles de violencia y actividades ilegales debido a la cesantía. empobrecimiento y miseria de amplios segmento de sus poblaciones. Entre ellas podemos señalar la prostitución de mujeres, hombres y niños, secuestros, ventas de niños, de órganos. tráfico y venta de drogas, robos de casas, automóviles y otros.

La respuesta a las acciones delictuales de los sectores más empobrecidos ha sido represión y brutalidad por parte de las autoridades de gobierno y las agencias crediticias internacionales. Grandes cantidades de recursos económicos han sido asignados al entrenamiento ! "modernización" de las numerosas fuerzas policiales para detener el crimen en vez de concentrase en la creación de centros productivos y programas capaces de generar recurso: económicos y empleos para los ejércitos de cesantes que asolan la región.

\section{Desarticulación de los trabajadores, rearticulación de las élites.}

Una característica notoria del neoliberalismo es su alarmante tendencia a restringir cada vez los empleos permanentes y la seguridad laboral. De este modo, el sector informal se transforma en la ruta abierta no sólo para compensar el creciente desempleo, sino que, a la vez, para obstruir los esfuerzos de los trabajadores a resistir este tipo de política y a forzarlos a buscar soluciones individuales. Como resultado de las políticas aplicadas por los regímenes neoliberales de América Latina y del Caribe las bases sociales y económicas de los sectores laborales se han debilitado enormemente.

La ideología neoliberal sostiene que todas las personas en la sociedad son iguales, en donde la competencia individual permite triunfar en cualquiera de sus niveles. En ese sentido, esta interpretación ideológica es un esfuerzo consciente a limitar los mecanismos de negociación colectiva de los sindicatos y federaciones laborales. Por esta razón, el neoliberalismo se opone a la sindicalización de los trabajadores o la limita al máximo para evitar conflictos laborales y otros mecanismos de presión utilizados para defender los intereses, derechos y conquistas de los sectores asalariados, lo que permite crear un ambiente favorable para las inversiones del gran capital nacional e internacional. En consecuencia. dentro de este modelo, los trabajadores se encuentran muy débilmente representados a diferencia de las sólidas organizaciones y movimientos históricamente desarrollados y observa- 
dos en el pasado. Sin lugar a dudas, las organizaciones laborales han experimentado un significativo debilitamiento y fragmentación como resultado de las acciones de los gobiernos militares que predominaron en la región entre 1964 y 1990, luego de sufrir una severa derrota en manos de las fuerzas armadas del continente y la administración de los Estados Unidos. Códigos laborales y constituciones políticas aprobadas como resultado de los gobiernos castrenses, sin la participación de los sectores laborales, prácticamente han paralizado las posibilidades de los trabajadores a negociar y a defender sus derechos y oportunidades.

Las consecuencias de la derrota militar del movimiento obrero por parte de las fuerzas armadas ha sido dramático, especialmente en algunos países del Cono Sur. Chile, por ejemplo, un país caracterizado por una histórica tradición laboral, constituye un caso muy significativo. En efecto, el número de trabajadores sindicalizados, que en 1972 correspondían al $41 \%$ de la fuerza laboral del país, durante los primeros años de la década de los ochenta no alcanzaban a más del 13\% (Ruiz-Tagle: 1985). Hasta el año 1973, cuando el golpe militar encabezado por el general Pinochet derrocara al presidente constitucional, Salvador Allende, existía una sola Central Unica de Trabajadores (CUT), la cual representaba a casi todos los trabajadores del país. Actualmente existen nueve centrales que incluyen 34 confederaciones y 25 federaciones, siendo la Confederación Unida de Trabajadores la más numerosa. A pesar que esta organización tiene las misma siglas que la otrora poderosa CUT, ésta no es más que un fantasma del poderoso pasado laboral chileno. La actual CUT agrupa a no más de 411.000 miembros, representando cerca del $17 \%$ de los trabajadores organizados y solamente al $4 \%$ de la fuerza laboral del país ${ }^{17}$ (Letelier, 12 de octubre de 1990).

También existen muchas otras alarmantes consecuencias bien conocidas y visibles del neoliberalismo, tales como la reaparición de enfermedades y epidemias erradicadas en el pasado, como el caso del cólera, tuberculosis, poliomielitis, etc., junto a los alarmantes índices de criminalidad y tráfico de drogas ya mencionados. Del mismo modo, es posible observar cada vez más niños en las calles dedicados a cualquier tipo de actividades, incluyendo la delincuencia y la prostitución, ancianos y jubilados carentes de todo tipo de recursos para sobrevivir, una creciente proletarización de las clases medias o pequeña burguesía, movimientos y concentraciones de poblaciones en sectorés urbanos, incluyendo la inmigración masiva e ilegal hacia el Norte.

\section{Neoliberalismo, el Tercer Mundo y el Medio Ambiente}

Durante las últimas décadas, el tema del medio ambiente se ha transformado en un tópico de gran preocupación en los países industrializados del Norte. Los habitantes de esos países han comenzado a mostrar una creciente preocupación y conciencia acerca del ambiente ecológico, a pesar de que mucho del daño ambiental al planeta ha alcanzado niveles prácticamente imposible de remediar. A través de tomar ventajas de los drásticos cambios experimentados en la balanza de las fuerzas económicas y políticas mundiales, las naciones mas poderosas e industrializadas proclaman en todas direcciones la naturaleza e impacto global de los problemas que afectan al medio ambiente y sus repercusiones. Las evaluaciones del problema ambientales llevadas a cabo por parte de las naciones desarrolladas del Norte, sin embargo, las eximen de sus propias responsabilidades y por el contrario, señalan a los países subdesarrollados y empobrecidos del Sur como los responsables directos del

${ }_{17}$ Estos datos fueron proporcionados el por parlamentario del Partido por la Democracia (PPD), diputado Juan Pablo Letclier, en un discurso pronunciado el 12 de octubre de 1990. 
deterioro ecológico que afecta al planeta. Esta situación, similarmente a las fórmulas económicas, se utiliza para imponer drásticos ajustes y medidas en las regiones del Tercer Mundo. De esta manera, por medio de la internalización de los problemas ambientales, la preocupación y movimiento ecológico es transformado en un elemento del nuevo orden mundial.

Sin pretender negar la importancia de que el problema ambiental es caótico en las regiones del Sur, no es justo acusar a dichas naciones por el daño de sus ecosistemas, tal como lo sugieren algunos medioambientalistas y gobiernos de los países industrializados del Norte. Organizadas como colonias en un pasado no lejano, y como naciones dependientes hoy día, estas regiones constituyen una base importante para la aplicación de políticas neocoloniales, incluyendo las políticas neoliberales actuales que producen nuevas formas de preservar el subdesarrollo y pobreza histórica del Tercer Mundo.

Mientras se culpa al Sur del deterioro del medio ambiente, el Norte, con solamente el $20 \%$ de la población mundial consume dos tercios de todos los metales y tres cuartos de los recursos energéticos que se producen en nuestro planeta. Para alcanzar los actuales niveles de vida y consumo de los países ricos e industrializados, el Norte ha contaminado el aire y saturado la atmósfera con gases, alterando incluso las condiciones climáticas de las diferentes regiones. Los bosques están desapareciendo y los desiertos extendiéndose aceleradamente. En ese sentido, es evidente que las patrones consumeristas de las naciones desarrolladas constituyen, sin lugar a dudas, la amenaza mayor de los ecosistemas mundiales.

Los pobres del Sur, históricamente privados del consumo de productos básicos, incluyendo alimentos, necesitan entonces tomar lo que puedan encontrar en sus medioambientes naturales para sobrevivir, incluso, al costo de destruirlos. La conducta consumerista del Norte y las necesidades de sobrevivencia de las poblaciones del Sur son, entonces, sistemas económicos ambientalmente insostenibles. De este modo, las preocupaciones ambientales de los países industrializados son totalmente diferentes de las naciones subdesarrolladas del Tercer Mundo. En otras palabras, mientras las preocupación central del Norte es la calidad de vida de la población, el problema en el Sur es la vida misma: alimentos, agua potable, vivienda, salud, educación, empleos, etc.

En este contexto vale entonces preguntarse: ¿Cómo pueden millones de individuos preocuparse del medio ambiente cuando sus vidas se consumen en una desesperada y angustiante batalla por sobrevivir bajo las más angustiantes condiciones de miseria y pobreza?

El debate internacional acerca del medioambiente ha generado el concepto de "desarrollo sostenible", entendido como una forma de iniciativa que permita satisfacer las necesidades actuales de la población sin comprometer las de las generaciones futuras. O sea, este tipo de desarrollo aspira a una etapa superior de evolución del medioambiente que asegure condiciones humanas mas equitativas para los habitantes del planeta.

Este concepto ubica correctamente a la ecología en el contex to global de nuestra sociedad y se concentra en la necesidad de originar acciones a nivel mundial para proteger las fuentes de vida para las generaciones venideras. En este contexto, tanto la pobreza como el crecimiento demográfico son identificados apropiadamente como algunos de los aspectos fundamentales de este modelo de desarrollo sostenible, en donde tanto la ecología y el desarrollo son entendidos como elementos interconectados entre si y no como algo irrecociliable como ha ocurrido tradicionalmente.

Sin embargo, la tesis del desarrollo sostenible contiene algunas contradicciones y limitaciones que requieren ser señaladas dentro de este nuevo ordenamiento mundial. Una de ellas consiste en que este modelo identifica a las disparidades económicas y sociales que afectan actualmente al Tercer Mundo, pero no reconoce los mecanismos históricos que ge- 
neraron dichas desigualdades. Una correcta y honesta interpretación de las problemas sociales que afectan al planeta debería reconocer que el proceso de subdesarrollo, que por más de cinco siglos ha afectado a los países del Tercer Mundo, es el resultado directo de la explotación y el pillaje por parte de las naciones más avanzadas del Norte. Actualmente, medidas tales como la división internacional del trabajo que crean y perpetúan la deuda externa, el proteccionismo, el comercio desigual, la fuga de capitales, emigraciones másivas, etc., son las consecuencias del daño ecológico.

Otra limitación de esta tesis es entender el desarrollo sostenible como una fórmula en donde la conservación ecológica, la igualdad social y los mejoramientos económicos de la población, junto a las fuerzas del mercado, pueden trabajar armónicamente. Bajo esta modelo, e] desarrollo sostenible se transforma en una utopía, dando la impresión de que todos los sectores de la sociedad se encuentran todos igualmente comprometidos en la protección del medio ambiente y la eliminación de la pobreza mundial. Desde esta perspectiva, conceptos tales como "mercado verde" y la "aldea global" han sido ampliamente difundidos y promovidos alrededor del mundo académico y político del Primer Mundo. ${ }^{18}$

Esta situación nos lleva hacia otra severa contradicción. De acuerdo a esta interpretación neoliberal, las mismas corporaciones multinacionales de los países industrializados que han sido los agentes más activos del deterioro ecológico y ambiental en el Tercer Mundo, deberían estar a cargo de la transición hacia un desarrollo ambiental afluente, limpio y justo.

No existen dudas al respecto que en la búsqueda de soluciones comunes para lograr resultados exitosos con respecto al desarrollo ambiental del los países atrasados se requiere del apoyo internacional. Sin embargo, este compromiso internacional se desvanece al momento de la transferencia de recurso financieros, regulaciones tecnológicas y comerciales. Este es el momento en que la teoría liberal del "mercado perfecto" elaborado durante la década de los ochenta adquiere una importante dimensión en el debate mundial acerca del medioambiente. La resurrección de la filosofía del libre juego del mercado como una solución infalible para resolver la crisis económica que afecta al mundo ha sido fuertemente promovida por los nuevos sectores financieros del industrializado Norte.

La creciente influencia de las políticas neoliberales no sólo están provocando impactos considerablemente negativos en las estructuras socio-politicas y económicas del Tercer Mundo, sino que, además, a sus ambientes ecológicos, como resultado de las medidas restrictivas monetaristas y el enfoque privatizador elaborado por el Fondo Monetario Internacional para las naciones deudoras. Algunas de estas recomendaciones reducen la participación del Estado al mínimo y fuerzan a introducir profundos cortes en los gastos públicos. De esta manera, los presupuestos destinados a la conservación ambiental. entre otros, son unos de los primeros items suprimidos en los programas de recuperación y austeridad económica impuestos por dichas agencias crediticias internacionales. Más importante, como resultado directo del esfuerzo para alcanzar un equilibrio en la balanza de pago lo antes posible, las naciones deudoras son forzadas a aumentar la afluencia de sus recursos naturales hacia e] Primer Mundo vía exportaciones, ignorando totalmente su impacto ecológico."

Como resultado, los ajustes neoliberales en las economías del Tercer Mundo no sólo

" De acuerdo a este concepto, las fuerzas del nercalo solanente garantizarán la creacion de bases sólidas para desarrollar un modelo socioeconómico y ambientat cquitativo. En verdad. este concepto dej "mercado verde" o ecológice. refleja la permiciosa influencia del neoliberalismo en discusiones acerca del desarollo y el medioamtiente. Esta tendencia favorece, entonces, an primera instancia. a aqueilas empresas económicas que buscan jegitimizar el uso y la comercializacion del medionabiente y la ecología.

${ }^{14}$ En el caso de Chile, por ejemplo. los productos madereros se han converudo en el segundo rubro de exportacion más importante después del cobre, alcanzado a los 1.6 mil millones de dólares en 1994. Sin embrago. solamente el $12 \%$ del territorio chileno nermanece reforestado comparado con el $66 \%$ en Brasil y $22 \%$ an la Argentina $(N A C L A$. Vol XXIX N 2 . Nov Dee 1905 p 5 ) 
son responsable por la creciente desigualdad y pobreza de esas naciones sino que, también. tienen un enorme costo y efecto ecológico y ambiental. En consecuencia, las fórmulas neoliberales constituyen la causa directa de las condiciones del subdesarrollo que afecta a dichas regiones y del daño ecológico que ha caracterizado al Tercer Mundo desde el momento mismo de su inserción en el sistema capitalista mundial.

\section{MIRANDO HACIA EL FUTURO}

Decidir en favor del desarrollo y el medio ambiente, es decir, inclinarse por su conservación y mejoramiento, necesariamente significa introducir drásticos cambios los antes posible. Como primera medida, las sociedades altamente industrializadas del Norte, como los grupos sociales con ingresos económicos elevados en el Sur, necesitan cambiar sus costumbres abiertamente derrochadoras y consumeristas. El modelo económico basado en el principio de la ganancia, que enfatiza el consumerismo ostentoso y que promueve el bienestar individual en vez del colectivo, es incompatible con las preocupaciones y problemas ecológicos que preocupan a nuestras sociedades. Por ejemplo, el $76 \%$ de todas las carreteras que existen para la circulación de vehículos en el mundo se encuentran en los países altamente industrializados. Sin lugar a dudas, este tipo de cultura debe ser reemplazada por un estilo de vida que conduzca a una utilización más racional de los recursos naturales y del medioambiente, sin sacrificar los niveles materiales existentes.

Una segunda medida consiste en introducir cambios radicales en las condiciones socioeconómicas del Tercer Mundo para erradicar las oprobiosas condiciones de miseria que afectan a sus poblaciones. Estos cambios requieren drásticas transformaciones del sistema de relaciones internacionales actuales como, a la vez, de sus estructuras sociales y económicas. En otras palabras, este es un desafío al modelo neoliberal y a la economía de libre mercado que promueven la pobreza, el hambre, enfermedades, poblaciones sobrante e ignorante en la mayoría de las naciones subdesarrolladas del Sur.

Obviamente, esta etapa requiere que las naciones del planeta, desarrollen una conciencia generalizada acerca de las condiciones en que se debate el Tercer Mundo, que a la vez. constituyen la fuente de origen de los innumerables problemas ambientales y ecológicos. Esta conciencia podría llegar a generar un nuevo modelo político basado en una verdadera cooperación internacional para confrontar la crisis ecológica, entendida de esta manera.

La caída del socialismo histórico en la Europa del este y el desmantelamiento de la ex Unión Soviética puso término a los temores políticos y militares por parte de las grandes potencias del Norte. Sin embargo, la cantidad de dinero que continúa gastándose -innecesariamente- en armamentos, es aún muy alta, sobrepasando los 800 mil millones de dólares al año. Las naciones subdesarrolladas del Sur, por su parte, contribuyen a esta carrera armamentista con 120 mil millones dólares anualmente. Así, como primera medida, resulta crucial entonces terminar con este inútil derroche de recursos para la destrucción y exterminación de la humanidad y la naturaleza, reorientándolos a la preservación y desarrollo de la vida humana y del planeta.

Insistamos una vez más que, tanto el problema del subdesarrollo como el del medioambiente no pueden ser resueltos en formas separadas, tal como lo sugiere el nuevo orden internacional. La solución debe considerar un plan en donde tanto el medioambiente como el desarrollo económico reconcilien las necesidades de los países pobres del Tercer Mundo y sus ecosistemas. Debido a que las víctimas históricas de las consecuencias del subdesarrollo han sido los habitantes de esas regiones resulta indispensable crear, entonces, un foro 
permanente en el Sur para la protección y diversificación biológica junto a un desarrollo bio-tecnológico.

Tal como se discutiera en la conferencia mundial acerca del medioambiente celebrada en Brasil, en junio de 1992, este forum debería considerar el desarrollo de varios mecanismos para discutir, analizar, evaluar, formular, proponer y ejecutar simultáneamente mecanismos y fórmulas tanto para el desarrollo, como la preservación ambiental. Algunos de los elementos a ser considerados, discutidos y analizados, deberían incluir, por ejemplo, aspectos tales como si es posible o no encontrar una solución a los desastrosos efectos de la impagable deuda externa que está aniquilando a las economías del Tercer Mundo, haciendo el desarrollo económico, político y social imposible en esas regiones.

¿Es posible formular tratados comerciales internacionales y políticas de mercados que incluyan los puntos de vistas y las necesidades de las naciones productoras del Sur? ¿Se encuentran los países del Norte preparados a competir sobre bases de equidad, sin imponer barreras protecionista y el sistema de cuotas a las naciones del Sur? ¿Está el Norte dispuesto a no continuar utilizando los alimentos y las medicinas como armas políticas para imponer sus propias fórmulas a aquellas naciones que demandan el derecho internacional de autodeterminación y no intervención, tal como ocurre con Cuba?

Estas no son las únicas interrogantes que conciernen al Tercer Mundo y muy especialmente a América Latina. ¿Es posible formular un sistema legal común para laprotección de los recursos genéricos que incluyan procedimientos para asegurar una compensación justa y adecuada a las naciones del Sur por el acceso a sus ricos recursos naturales? ¿Es posible implementar mecanismos comunes para facilitar acceso a la biotecnología utilizando materiales genéricos, tanto en el Norte como en el Sur?

Por otra parte, también existen algunas preocupaciones concernientes a las poblaciones mismas. ¿Es posible llegar a un acuerdo sobre proyectos y políticas que aseguren las culturas, lenguas, estilos de vida y tradiciones de los pueblos indígenas junto al rico conocimiento que poseen acerca de como vincular adecuadamente a los seres humanos con el medioambiente? ¿Es posible crear mecanismos de defensa común para proteger el resultado de las investigaciones realizadas en el Tercer Mundo?

Finalmente, y quizás más importante, no está demás plantearse la siguiente pregunta: ¿Es posible desarrollar una conciencia política, económica y ecológica en la población de los países industrializados del Primer Mundo, para que trabajen conjuntamente con los pueblos del Tercer Mundo, para atacar y erradicar todos los problemas discutidos hasta aquí?

\section{BIBLIOGRAFÍA}

Burbach, Roger. "Rupture Frontiers: The Transformation of the US-Latin American System" aparecida en el Soctulst Register 1992. editado por Miliband, Ralph y Panitch. Leo. (The Merlin Press. 1992).

Castro Fidel. Tomorrow Will Be To Late. (Ocean Press, 1993).

Chalmers. Douglas. "Developing in the Periphery: Externa! Factors in Latin Anerican Politics", publicado en Power and Social Control: Social Structures and their Transfonmations, edited by Tom Burns and Waller Buckley. (Beverly Hills: Sage, 1976).

Gilbert. Jorge. The Aftermath of the Militay State in Lain America. (TESC: Olympia. 1991)

Gorostiaga. Xabier. Anuario del Centroregind de luestiguiones yocides (CRIES) (Universidad Centroamericana: Managua. $\cdot 993)$.

Itoh. Makoto. "Japan in the New World". publicado en The Socialist Register 1992, editado por Ralph Miliband y Leo Pantch. he Merlin Press: 1992). 
Lederma, Michael. "Salinas Plans Major Sell-Off" en el Washington Rejont on the Hemisphere. del 14 de noviembre de 1940.

Neff, Jorge Democratic Transition and the Entrenchment of Authonatian Copitalism in Chile. Paper presentadoen la conferencia acerca de América Latina. Rockey Mountain Conference, celebrada en la ciudad de Vancouver. British Columbia, Canadá. entre el 31 de marzo y el 4 de abril de 1993.

Marx, Karl."18th Brumaire" en Solected Work (un volumen). (Moscow: Progrees Publishers, N.Y., 1965$).$

Petras. Janes y Morley, Morris. Latin Americu in Times of Cholerc. (Rouldedge. 1992).

Richard, Pablo. "Liberation Theology: Theology of the South", aparecido en la revista Emio. volumen 12. N" 143 de junio de 1993.

Saunders. John. "Open Season on Indigent Americans" publicado en el Globe amd Mail Repont on Business, del 18 de enero de 1992.

Vasconi, Tomás A. Gran capital y militarización én América Latina. (ERA: México. 1976). 